\title{
Contribuições Teóricas Recentes ao Estudo da Criatividade ${ }^{1}$
}

\author{
Eunice M. L. Soriano de Alencar ${ }^{2}$ \\ Universidade Católica de Brasília \\ Denise de Souza Fleith \\ Universidade de Brasília
}

\begin{abstract}
RESUMO - O artigo apresenta três abordagens recentes no estudo da criatividade, a saber: a Teoria do Investimento em Criatividade, de Sternberg, o Modelo Componencial da Criatividade, de Amabile, e a Perspectiva de Sistemas, de Csikszentmihalyi. Esses teóricos atribuem a produção criativa a um conjunto de fatores, que interagem de forma complexa, referentes tanto ao indivíduo quanto a variáveis sociais, culturais e históricas do ambiente onde o indivíduo se encontra inserido. Tais abordagens contrastam com contribuições teóricas anteriores pela ênfase a distintos elementos do contexto social, que oportunizam e reconhecem, em maior ou menor extensão, a expressão criativa.
\end{abstract}

Palavras-chave: teorias recentes de criatividade; modelos de criatividade; ambiente.

\section{Recent Theoretical Contributions to the Study of Creativity}

\begin{abstract}
The paper presents three recent approaches to the study of creativity: Sternberg's Investment Theory of Creativity, Amabile's Componential Model of Creativity, and Csikszentmihalyi's Systems Perspective of Creativity. These authors state that the creative production is the result of a set of factors which interact in a complex way, referring to the person as to the social, cultural, and historical variables of the environment in which he/she is included. Such approaches contrast with previous theoretical contributions by emphasizing distinct elements of the social context which nurture and recognize, to different degrees, the creative expression.
\end{abstract}

Key words: recent theories of creativity; models of creativity; environment.

Quando se examina a literatura sobre Psicologia da Criatividade no Brasil, observa-se que contribuições teóricas recentes não têm sido tradicionalmente contempladas. De modo geral, são os aportes especialmente da teoria psicanalítica, da Gestalt, dos representantes da Psicologia Humanista, paralelamente ao papel dos hemisférios cerebrais na produção criativa, o que é mais divulgado e discutido.

Tanto Alencar (1995) como Wechsler (1993) e Kneller (1976), por exemplo, fazem menção aos estudos de Freud. Este via no inconsciente as origens tanto da neurose como da criatividade, tendo realizado estudos de caso de pessoas eminentes, como Leonardo da Vinci, considerando o seu trabalho criativo como uma sublimação de complexos reprimidos. As concepções de neopsicanalistas, como Kris e Kubie, que deram uma ênfase especial ao pré-consciente no processo criativo, são também conhecidas. Outra teoria que trouxe contribuições ao estudo da criatividade foi a Gestalt. Esta deu início às pesquisas sobre o insight, ou seja, aquele momento do processo criativo em que surge, usualmente de forma repentina, uma nova idéia ou solução para um problema. Ademais, os teóricos da Gestalt, especialmente Wertheimer (1959), também relacionaram o pensamento produtivo com os processos de pensamento que ocorrem no trabalho criativo, como naquele de cientistas eminentes. Os representantes da Psicologia Humanista, como Rogers, Maslow e Rollo May,

1 Ambas as autoras contribuíram de forma equivalente na preparação do artigo.

2 Endereço para correspondência: Programa de Mestrado em Educação, Universidade Católica de Brasília, SGAN 916 Módulo B, Asa Norte, 70790-160, Brasília, DF E-mail: ealencar@ pos.ucb.br são também reconhecidos pelas suas incursões sobre a origem da criatividade e condições necessárias para a sua expressão. Todos eles chamaram a atenção para a tendência humana em direção à auto-realização como força mobilizadora da criatividade. Consideram ademais que não basta o impulso interno para se auto-realizar. É ainda indispensável um ambiente que propicie liberdade de escolha e de ação, com reconhecimento e estimulação do potencial para criar de cada indivíduo. Os processos de pensamento que ocorrem nos distintos hemisférios cerebrais, sendo o hemisfério esquerdo mais eficiente nos processos de pensamento descritos como verbais, lógicos e analíticos, enquanto que no hemisfério direito ocorreriam padrões de pensamento mais associados à criatividade, têm sido extensamente divulgados.

Nos últimos 20 anos, novas contribuições teóricas surgiram, englobando distintos componentes considerados necessários para a ocorrência da criatividade. Até os anos 70, o objetivo era delinear o perfil do indivíduo criativo e desenvolver programas e técnicas que favorecessem a expressão criativa. Após essa data, os estudiosos voltaram sua atenção, de forma mais sistemática, para a influência de fatores sociais, culturais e históricos no desenvolvimento da criatividade. Sob essa perspectiva, a produção criativa não pode ser atribuída exclusivamente a um conjunto de habilidades e traços de personalidade do criador, mas também sofre a influência de elementos do ambiente onde esse indivíduo se encontra inserido (Hennessey \& Amabile, 1988). Mais especificamente, a abordagem individual foi substituída por uma visão sistêmica do fenômeno criatividade (Feldman, Csikszentmihalyi \& Gardner, 1994). Como resultado, vários estudos têm sido 
conduzidos com o objetivo de investigar variáveis do contexto sócio-histórico-cultural que interferem na produção criativa e favorecem a expressão do comportamento criativo (Amabile, 1996; Feldman, 1994; Gardner, 1993; Gruber \& Davis, 1988; Simonton, 1994). Para Csikszentmihalyi (1996), por exemplo, "é mais fácil desenvolver a criatividade das pessoas mudando as condições do ambiente, do que tentando fazê-las pensar de modo criativo" (p. 1). Neste sentido, para se compreender porque, quando e como novas idéias são produzidas, é necessário considerar tanto variáveis internas quanto variáveis externas ao indivíduo.

Três modelos de criatividade foram elaborados com base nessa abordagem recente: a teoria de investimento em criatividade de Sternberg (1988, 1991; Sternberg \& Lubart, 1991, 1993, 1995, 1996), o modelo componencial de criatividade de Amabile (1983, 1989, 1996) e a perspectiva de sistemas de Csikszentmihalyi (1988a, 1988b, 1988c, 1996). Esses modelos serão descritos a seguir.

\section{A Teoria do Investimento em Criatividade - Sternberg}

Em sua formulação inicial de uma teoria da criatividade, Sternberg (1988), embora considerasse que um modelo completo deste fenômeno devesse incluir tanto o ambiente como variáveis pessoais que facilitam ou impedem a manifestação da criatividade, restringiu-se a alguns atributos internos do indivíduo que contribuem para o funcionamento criativo, dando destaque à inteligência, estilo cognitivo e personalidade/motivação. Em anos posteriores, Sternberg (1991) e Sternberg e Lubart $(1991,1993,1995,1996)$ ampliaram o modelo originalmente formulado, considerando o comportamento criativo como resultado da convergência de seis fatores distintos e inter-relacionados, apontados como recursos necessários para a expressão criativa. Estes seriam: (a) inteligência, (b) estilos intelectuais, (c) conhecimento, (d) personalidade, (e) motivação e (f) contexto ambiental.

A sua teoria, a que Sternberg e Lubart (1991, 1995, 1996) denominam teoria do investimento ${ }^{3}$, inclui distintos elementos que foram anteriormente ressaltados por outros estudiosos como relevantes para a produção criativa. Inclui, por exemplo, aspectos presentes no modelo componencial proposto por Amabile (1983), que descreve a criatividade como resultado da motivação, habilidades relevantes de domínio e processos criativos relevantes. Engloba também traços de personalidade, aspecto este altamente enfatizado nas contribuições de MacKinnon (1965) e Barron (1969), que investigaram atributos de personalidade de profissionais de áreas diversas que se destacaram por sua produção criativa. Tem ainda elementos comuns com a abordagem sistêmica de Csikszentmihalyi (1988a, 1988b, 1988c), que considera a criatividade como resultado de elementos da pessoa, do

3 Esta nomenclatura constitui-se em uma metáfora com o mercado financeiro, uma vez que considera que as pessoas criativas são aquelas dispostas a "comprar barato e vender caro" no plano de idéias. Conforme lembram os autores, "comprar barato" significa perseguir idéias que são desconhecidas, mas que o indivíduo percebe como sendo potencialmente valiosas. Por outro lado, "vender caro" envolve partir para novos projetos quando uma idéia ou produto se torna valioso, já tendo possibilitado um retorno significativo. domínio (área do conhecimento) e do campo (especialistas de uma área específica que têm o poder de determinar a estrutura do domínio); de Simonton (1988), que investigou determinantes ambientais e históricos da criatividade; e ainda da teoria triárquica da inteligência proposta pelo próprio Sternberg (Sternberg, 1985).

Ao descrever os seis fatores que convergem para a produção criativa, ressaltam Sternberg e Lubart (1991) que nem todos os elementos de cada um desses recursos são relevantes para a criatividade, devendo ainda cada um deles ser visto de forma interativa com os demais e jamais de forma isolada, salientando: "alta inteligência na ausência de motivação, ou conhecimento amplo na ausência de habilidade intelectual para compreender e utilizar tal conhecimento, levará no máximo a níveis moderados de performance criativa" (pp. 4-5). Propõem, entretanto, que um alto nível de recurso motivacional pode contrabalançar um contexto ambiental menos propício, embora lembrem também que nem sempre um alto nível de um dos seis recursos possa compensar por um outro que se encontra ausente ou quase ausente.

\section{Inteligência}

Com relação à inteligência, Sternberg e Lubart (1995, 1996) consideram que especialmente três habilidades cognitivas são importantes. A primeira diz respeito à habilidade sintética de redefinir problemas, ou seja, a habilidade de ver o problema sob um novo ângulo; a segunda seria a habilidade analítica de reconhecer dentre as próprias idéias aquelas em que valeria a pena investir; e a terceira, a habilidade prática-contextual, diz respeito a ser capaz de persuadir outras pessoas sobre o valor das próprias idéias. Sternberg e Lubart vão além, sublinhando que a confluência destas três habilidades é importante. Consideram, por exemplo, que habilidade analítica utilizada na ausência das duas outras habilidades geraria pensamento crítico, mas não criativo ou que habilidade sintética na ausência das duas outras habilidades geraria novas idéias, porém não necessariamente idéias promissoras ou aplicáveis.

Lembram estes autores que, de modo geral, soluções mais criativas são o resultado da capacidade de se redefinir um dado problema, o que ocorre, por exemplo, como conseqüência do insight. Propõem ainda três tipos básicos de insight: o primeiro (insight de codificação seletiva) ocorreria quando alguém que está tentando resolver um problema reconhece a relevância de informações que podem não ser imediatamente óbvias, apontando como exemplo a descoberta da penicilina por Alexandre Fleming. O segundo tipo de insight (insight de comparação seletiva) envolveria o pensamento analógico, quando informações do passado são aproveitadas para resolver problemas do presente, percebendo-se uma analogia entre o velho e o novo; o terceiro tipo de insight (insight de combinação seletiva) ocorre quando se reúnem informações cuja conexão não é óbvia.

\section{Estilos Intelectuais}

Sternberg (1991) lembra que há três estilos intelectuais, os quais se referem à forma como a pessoa usa, explora ou utiliza a sua inteligência, denominando-os: legislativo, executivo e 
judiciário. O primeiro estaria presente naquela pessoa que gosta de formular problemas e criar novas regras e maneiras de se ver as coisas, sendo particularmente importante para a criatividade. Uma pessoa com esse estilo tem prazer em criar as suas próprias regras e trabalhar em problemas que não sejam pré-fabricados. As pessoas criativas seriam, pois, mais propensas a preferir o estilo legislativo. $\mathrm{O}$ segundo estaria presente naquela pessoa que gosta de implementar idéias, com preferência por problemas que apresentam uma estrutura clara e bem definida. O terceiro caracterizaria aquelas que têm preferência por emitir julgamentos, avaliar pessoas, tarefas e regras, tendo prazer em emitir opiniões e avaliar as dos demais.

Segundo Sternberg, as pessoas têm preferências por um determinado estilo e ainda que o sistema educacional tende a encorajar nas pessoas o estilo executivo. Isto por quê, na escola, os alunos, de modo geral, recebem os problemas já estruturados, sendo muitas vezes punidos quando extrapolam a estrutura apresentada. Esta tem sido uma crítica feita a sistemas educacionais de distintos países, embora mais recentemente observa-se um movimento no sentido de se promover uma cultura de aprendizagem que privilegie também o exercício de resolução de problemas sem uma estrutura pré-determinada.

\section{Conhecimento}

Um terceiro componente da teoria proposta por Sternberg e Lubart $(1991,1995)$ é o conhecimento. Lembram estes autores que, para dar uma contribuição significativa a uma determinada área, é de fundamental relevância ter o conhecimento sobre aquela área. Ressaltam ainda que sem tal conhecimento, corre-se o risco de se descobrir o que já se sabe, deixando de se identificar problemas da área efetivamente importantes. Os autores discriminam também dois tipos de conhecimento: o formal e o informal, considerando ambos importantes para a criatividade. $\mathrm{O}$ primeiro seria aquele conhecimento de uma determinada área ou de um dado trabalho que se adquire através de livros, palestras ou qualquer outro meio de instrução. $\mathrm{O}$ informal seria aquele que se adquire por meio de dedicação a uma determinada área, sendo raramente ensinado explicitamente e, a maior parte das vezes, impossível sequer de ser verbalizado.

Ainda com relação a este componente, estes teóricos (Sternberg \& Lubart, 1995, 1996) sublinham que a criatividade em grande número de áreas requer o conhecimento do que vem ocorrendo naquela área específica, sendo, entretanto, necessário se libertar dos limites e entraves daquele conhecimento. Justificam lembrando que ao mesmo tempo em que um vasto conhecimento permite um maior número de associações e isto é benéfico para a criatividade, pode também dificultar à pessoa visualizar de uma forma diferente questões de interesse do domínio.

\section{Personalidade}

Quanto à personalidade, outro componente da teoria de Sterberg e Lubart, lembram os autores que alguns traços de personalidade contribuem mais do que outros para a expressão da criatividade, destacando as pessoas com alta produção criativa pela apresentação de um conjunto de traços de personalidade, como predisposição a correr riscos, confiança em si mesmo, tolerância à ambigüidade, coragem parar expressar novas idéias, perseverança diante de obstáculos e ainda um certo grau de auto-estima, embora nem todos eles estejam necessariamente presentes.

Especialmente a tolerância à ambigüidade é vista como condição sine qua non para a performance criativa em distintas áreas. Isto por quê as idéias necessitam de tempo para amadurecer. De forma similar, soluções para distintas modalidades de problemas muitas vezes são alcançadas através de aproximações sucessivas. Caso o indivíduo não apresente este traço, há maiores chances de chegar a soluções inadequadas em função de um fechamento prematuro e impulsivo.

A perseverança diante de obstáculos é também um atributo que se destaca na pessoa criativa, como pôde ser observado inclusive em estudo de nossa autoria (Alencar, Neves-Pereira, Ribeiro \& Brandão, 1998) com amostra de pesquisadores que se destacavam por sua produção criativa e que consideraram este traço como um dos que mais havia contribuído para a sua produção superior. Persistência diante dos obstáculos e dedicação ao trabalho foram também lembrados por esses pesquisadores como de fundamental importância para justificar uma realização bem-sucedida em suas atividades de investigação.

Como aponta Sternberg (1988), a questão não é se a pessoa irá ou não encontrar obstáculos, mas antes como irá lidar com os mesmos e o grau de determinação em não se deixar abater diante das adversidades que possivelmente terá que enfrentar para alcançar as suas metas.

Sternberg e Lubart (1995) ressaltam também que esses traços, embora sejam predisposições relativamente estáveis, podem sofrer mudanças ao longo do tempo, sendo ainda influenciados pelas condições ambientais. A autoconfiança, por exemplo, dificilmente será apresentada por aqueles que tiveram experiências persistentes de fracasso. Por outro lado, vários deles são desestimulados pelos agentes socializadores que, muitas vezes, não alimentam a auto-estima, a perseverança diante de obstáculos, a coragem para expressar idéias divergentes, não oferecendo oportunidades para seu fortalecimento, como foi observado por inúmeros autores, como Torrance (1975) e Alencar e Rodrigues (1978) em estudos sobre o perfil do aluno ideal. Nesses estudos, traços que se associam à criatividade não foram considerados desejáveis por número substancial de professores. Entretanto, Sternberg e Lubart (1995) defendem ainda a idéia de que estes atributos estão parcialmente sob o controle da pessoa, podendo a mesma desenvolvê-los caso o deseje.

\section{Motivação}

Os recursos motivacionais dizem respeito às forças impulsionadoras da performance criativa. Especialmente a motivação intrínseca, centrada na tarefa, é de inestimável importância para a criatividade, uma vez que as pessoas estão muito mais propensas a responder criativamente a uma dada tarefa, quando estão movidas pelo prazer de realizá-la. Este aspecto foi observado em vários estudos revistos por Sternberg e Lubart (1995) com profissionais que vinham realizando trabalhos altamente criativos em distintas áreas, e 
que se diziam mobilizadas pelo amor pela tarefa, focalizando muito mais sua atenção e energia no trabalho em si do que em possíveis prêmios ou reconhecimento por sua realização.

Consideram, entretanto, que ambos os tipos de motivação - intrínseca e extrínseca, estão freqüentemente em interação, combinando-se mutuamente para fortalecer a criatividade. Neste sentido, Sternberg e Lubart citam várias pesquisas que apontam o papel mobilizador tanto da motivação intrínseca como da extrínseca para a criatividade. Em um destes estudos, desenvolvido por Ochse (em Sternberg \& Lubart, 1995), investigaram-se motivadores considerados especialmente relevantes por pessoas que vinham dando contribuições criativas em áreas diversas. Notou-se que, dentre estes, vários foram lembrados, alguns que refletiam uma motivação intrínseca e outros que traduziam uma motivação extrínseca. Alguns exemplos: (a) o desejo de obter domínio sobre um dado problema; (b) o desejo de se obter reconhecimento; (c) o desejo de se alcançar auto-estima; (d) o desejo de se alcançar imortalidade; (e) o desejo de se descobrir uma ordem subjacente nas coisas.

\section{Contexto Ambiental}

Um último componente presente na teoria de Sternberg e Lubart diz respeito ao contexto ambiental. Sabe-se que a criatividade não ocorre no vácuo e não pode ser vista fora deste contexto, especialmente porque tanto a pessoa como o produto são julgados e avaliados como criativos ou não por pessoas do seu contexto social. Entretanto, o tipo de ambiente que facilita o desenvolvimento e realização do potencial criativo depende também de outros fatores, como, por exemplo, do nível do potencial criativo da pessoa e da área em que a pessoa criativa se expressa. Desta forma, o ambiente que facilita a expressão criativa interage com variáveis pessoais e situacionais de uma forma complexa.

Ainda segundo Sternberg e Lubart, o contexto ambiental afeta a produção criativa de três maneiras distintas: (a) grau em que favorece a geração de novas idéias; (b) extensão em que encoraja e dá o suporte necessário ao desenvolvimento das idéias criativas, possibilitando a geração de produtos tangíveis; e (c) avaliação que é feita do produto criativo.

Estes autores analisaram diferentes tipos de ambientes como, por exemplo, o ambiente dominante na família, na escola, em organizações (ambiente de trabalho) e ainda fatores da sociedade que contribuem para a expressão criativa entre seus membros, fundamentando-se em inúmeros estudos onde estes distintos ambientes foram objeto de investigação, como, por exemplo, os estudos de Arieti (1976) sobre sociedades criativogênicas, Chambers (1973) sobre o perfil de professores que facilitam a criatividade, e de Amabile e Gryskiewicz (1989) sobre elementos presentes em ambientes de trabalho que promovem a criatividade. Como estes estudos já foram descritos em outros textos de nossa autoria (Alencar, 1995, 1996) não serão reapresentados aqui.

\section{Modelo Componencial de Criatividade - Amabile}

Segundo Amabile (1996), "um produto ou resposta será julgado como criativo na medida em que (a) é novo e apropriado, útil, correto ou de valor para a tarefa em questão, e (b) a tarefa é heurística e não algorítmica" (p. 35). Em sua definição de criatividade, Amabile ressalta aspectos como originalidade e adequação da resposta, bem como chama atenção para a necessidade da tarefa proposta possibilitar vários caminhos para a solução do problema. Com base nessa definição, essa autora elaborou um modelo componencial de criatividade.

O modelo proposto por Amabile (1983, 1989, 1996) procura explicar como fatores cognitivos, motivacionais, sociais e de personalidade influenciam no processo criativo. Grande ênfase, porém, é dada ao papel da motivação e dos fatores sociais no desenvolvimento da criatividade. O modelo consiste de três componentes necessários para o trabalho criativo: habilidades de domínio, processos criativos relevantes e motivação intrínseca. Na versão original do modelo (Amabile, 1983), o segundo componente, processos criativos relevantes, era denominado de habilidades criativas relevantes. A mudança foi proposta por Amabile (1996), pois um dos elementos desse componente, traços de personalidade, não é, geralmente, considerado uma habilidade. Para Amabile, para que a criatividade ocorra é necessário que os três componentes estejam em interação.

O componente habilidades de domínio inclui vários elementos relacionados ao nível de expertise em um domínio, tais como talento, conhecimento, adquirido através de educação formal e informal, experiência e habilidades técnicas na área. Embora, alguns desses elementos possam ser considerados inatos (como por exemplo, boa memória auditiva para reproduzir sons musicais), educação e experiência contribuem também para o seu desenvolvimento (Amabile \& Tighe, 1993). Em suma, contribuições criativas não ocorrem no vácuo, mas estão alicerçadas em um amplo conhecimento da área em que se está atuando. Conforme assinala Starko (1995), é necessário ter muito conhecimento sobre uma área de modo a transformá-lo, derivar implicações do mesmo e combiná-lo de diferentes maneiras.

$\mathrm{O}$ segundo componente diz respeito ao que Amabile se refere como processos criativos relevantes e inclui estilo de trabalho, estilo cognitivo, domínio de estratégias que favorecem a produção de novas idéias e traços de personalidade. Tais elementos influenciam no uso que se faz das habilidades de domínio. Por exemplo, analisar uma informação sob diferentes pontos de vista, ou através de metáforas, pode contribuir para melhor compreensão do domínio. Segundo Amabile (1989), o estilo de trabalho criativo é caracterizado como habilidade de se concentrar por longos períodos de tempo, dedicação ao trabalho, alto nível de energia, persistência frente a dificuldades, busca da excelência e habilidade de abandonar idéias improdutivas.

Com relação ao estilo cognitivo, os seguintes aspectos podem ser destacados: quebra de padrões usuais de pensamento, quebra de hábitos, compreensão de complexidades, produção de várias opções, suspensão de julgamento no momento de geração de idéias, flexibilidade perceptual, transferência de conteúdos de um contexto para outro e armazenagem e recordação de idéias. O domínio de estratégias que favorecem a produção de novas idéias está alicerçado em princípios heurísticos tais como: (a) torne o familiar estranho, (b) gere hipóteses, use analogias, investigue incidentes paradoxais, e (c) brinque com as idéias. 
Segundo Amabile (1996), traços de personalidade podem contribuir para o desenvolvimento dos processos criativos relevantes. Dentre os traços de personalidade que favorecem a produção criativa, podemos ressaltar a autodisciplina, persistência, independência, tolerância por ambigüidades, não conformismo, automotivação e desejo de correr riscos. Para Amabile, esses estilos e traços podem ser desenvolvidos na infância e mesmo na vida adulta.

O terceiro componente do modelo de criatividade de Amabile é a motivação intrínseca. Embora possa ser considerada, em parte, inata, a motivação intrínseca pode ser cultivada, em larga escala, pelo ambiente social. Motivação intrínseca diz respeito à satisfação e envolvimento que o indivíduo tem pela tarefa, independente de reforços externos, e engloba interesse, competência e autodeterminação. Provavelmente um indivíduo vai se sentir mais motivado quando a atividade captura seu interesse, é desafiadora, leva-o a desenvolver sentimentos de auto-eficácia e a se envolver com a atividade por conta própria. É importante mencionar que "não existe tal coisa chamada 'atividade intrinsecamente interessante.' Uma atividade pode ser intrinsecamente interessante para uma pessoa em particular, em um período de tempo específico" (Amabile, 1989, p. 54).

Motivação intrínseca pode levar o indivíduo a buscar mais informações sobre a área estudada e, conseqüentemente, desenvolver as suas habilidades de domínio. Da mesma maneira, altos níveis de motivação intrínseca podem levar o indivíduo a se arriscar e a romper com estilos de produção de idéias habitualmente empregados, contribuindo para o desenvolvimento de novas estratégias criativas (Hill \& Amabile, 1993).

Por outro lado, a motivação extrínseca pode minar, em parte, o processo criativo (Amabile, 1983, 1996). Motivação extrínseca diz respeito ao envolvimento do indivíduo em uma tarefa com o objetivo de alcançar alguma meta externa à tarefa e é marcada pela recompensa e reconhecimento externos. Existem, entretanto, dois tipos de motivação extrínseca. Um pode levar o indivíduo a se sentir controlado. Neste sentido, Hennessey e Amabile (1988) e Collins e Amabile (1999) têm chamado a atenção para o efeito prejudicial de aspectos como recompensa, escolha restrita, competição e avaliação externa no processo criativo. Segundo esses autores, tais aspectos influenciam negativamente no nível de interesse e desempenho do indivíduo na tarefa. O outro tipo de motivação extrínseca provê informação contribuindo para que o indivíduo complete a tarefa com sucesso. Para Amabile (1996), "motivação intrínseca conduz à criatividade; motivação extrínseca controladora é deletéria à criatividade, mas motivação extrínseca informativa pode conduzir à criatividade, particularmente se há altos níveis iniciais de motivação intrínseca" (p. 119).

O modelo de criatividade proposto por Amabile inclui cinco estágios $(1983,1996)$. O primeiro estágio é denominado identificação do problema ou da tarefa. Nesse estágio, o indivíduo identifica um problema específico como tendo valor para ser solucionado. Caso o indivíduo tenha um nível alto de motivação intrínseca pela tarefa, esse interesse será suficiente para engajá-lo no processo. O segundo estágio envolve a preparação, momento em que o indivíduo constrói ou reativa um estoque de informações relevantes para a solução do problema. Importante nesse estágio é o desenvolvimento de habilidades de domínio. No terceiro estágio, denominado geração de resposta, o nível de originalidade do produto ou resposta é determinado. Nesse estágio, o indivíduo gera várias possibilidades de respostas, fazendo uso dos processos criativos relevantes e de sua motivação intrínseca.

No quarto estágio ocorre a comunicação e validação da resposta. Segundo Amabile (1996), uma idéia não pode permanecer apenas na mente do indivíduo que a produziu, caso contrário, nenhum produto observável será gerado. É necessário que o criador comunique sua idéia ou produto de alguma maneira. A idéia produzida deve ser ainda testada. Neste sentido, o indivíduo faz uso de suas habilidades de domínio para avaliar a extensão em que o produto ou resposta será criativa, útil, correta e de valor para a sociedade de acordo com critérios estabelecidos pelo domínio. O quinto e último estágio, denominado resultado, representa a tomada de decisão com relação à resposta, com base na avaliação do estágio anterior. Caso a resposta ou produto tenha solucionado o problema com sucesso, o processo termina. $\mathrm{Da}$ mesma forma, caso a resposta gerada tenha sido considerada um fracasso total, o processo também é finalizado. Por outro lado, se a resposta produzida é parcial, ou seja, representa um progresso em direção à solução do problema, o processo retorna aos estágios anteriores. De qualquer forma, o conhecimento adquirido nesse processo será incorporado ao repertório de habilidades de domínio. Espera-se também que experiências prévias com o problema produzirão respostas mais criativas em momentos posteriores de envolvimento com a tarefa. Entretanto, no caso de resultados parciais ou de insucesso, é essencial que o indivíduo se sinta motivado para dar continuidade ao trabalho ou reiniciá-lo (Amabile, 1983, 1996). É importante ressaltar ainda que esses estágios não ocorrem, necessariamente, em uma sequiência lógica.

Embora o modelo proposto por Amabile inclua predominantemente componentes intraindividuais, $\mathrm{o}$ ambiente exerce influência crucial sobre cada um deles em todas as etapas do processo criativo (Amabile \& Tighe, 1993). Segundo Amabile (1995):

Para a maioria dos leigos, e muitos pesquisadores, criatividade é uma qualidade de pessoas, uma constelação de traços de personalidade, características cognitivas e estilo pessoal. Se nós mudarmos essa perspectiva dispositiva para uma que admita a possibilidade de fortes influências sociais na criatividade, nós devemos abandonar a definição centrada na pessoa. Agora, criatividade torna-se uma qualidade de idéias e produtos que é validada pelo julgamento social, e explicações de criatividade podem englobar características da pessoa, fatores situacionais, e a complexa interação entre eles. (p. 424)

Neste sentido, Amabile $(1983,1989,1996)$ sugere alternativas de estimulação da criatividade em sala de aula ou no ambiente de trabalho: (a) encorajar autonomia do indivíduo, evitando controle excessivo e respeitando a individualidade de cada um; (b) cultivar a autonomia e independência enfatizando valores ao invés de regras; (c) ressaltar as realizações ao invés de notas ou prêmios; (d) enfatizar o prazer no ato de aprender; (d) evitar situações de competição; (e) expor os indivíduos a experiências que possam estimular sua criatividade; (f) encorajar comportamentos de questionamento e 
curiosidade; (g) usar feedback informativo; (h) dar aos indivíduos opções de escolha; e (i) apresentar pessoas criativas como modelos.

\section{A Perspectiva de Sistemas - Csikszentmihalyi}

Csikszentmihalyi (1988b) defende a idéia de que o foco dos estudos em criatividade deve ser nos sistemas sociais e não apenas no indivíduo. Para ele, o fenômeno criatividade é construído por meio da interação entre o criador e a sua audiência. Conforme explica Csikszentmihalyi (1996), "criatividade não ocorre dentro dos indivíduos, mas é resultado da interação entre os pensamentos do indivíduo e o contexto sócio-cultural. Criatividade deve ser compreendida não como um fenômeno individual, mas como um processo sistêmico" (p. 23). Neste sentido, mais importante do que definir criatividade é investigar onde ela se encontra, ou seja, em que medida o ambiente social, cultural e histórico reconhece ou não uma produção criativa. Portanto, criatividade não é resultante do produto individual, mas de sistemas sociais que julgam esse produto (Csikszentmihalyi, 1999).

O modelo de sistemas propõe, pois, criatividade como um processo que resulta da intersecção de três fatores: indivíduo (bagagem genética e experiências pessoais), domínio (cultura) e campo (sistema social). O indivíduo é quem produz variações e introduz mudanças no domínio ou área de conhecimento. Com relação ao indivíduo, dois aspectos são apontados - características associadas à criatividade e background social e cultural. Dentre as características mais salientes de indivíduos criativos estão a curiosidade, entusiasmo, motivação intrínseca, abertura a experiências, persistência, fluência de idéias e flexibilidade de pensamento. Csikszentmihalyi (1999) informa, entretanto, que as pessoas criativas não se caracterizam por uma estrutura rigidamente estabelecida, mas ajustam essas características conforme a ocasião. Elas possuem a habilidade de operar em uma ampla gama de dimensões da personalidade de forma a atender as demandas da situação. Neste sentido, elas podem, em determinados momentos ou fases de produção, apresentar características de introversão e, em outras, de extroversão. Também importante é estar inserido em um ambiente que estimule a produção criativa, valorize o processo de aprendizagem, ofereça oportunidades de acesso e atualização do conhecimento, propicie o acesso a mentores e recursos como livros, computadores etc. Expectativas parentais positivas com relação ao desempenho do filho na vida escolar e profissional e apoio familiar no que diz respeito aos interesses apresentados pela criança constituem também aspectos relevantes de background que favorecem a expressão criativa.

O segundo componente desse modelo é o domínio, que consiste de um conjunto de regras e procedimentos simbólicos estabelecidos culturalmente, ou seja, conhecimento acumulado, estruturado, transmitido e compartilhado em uma sociedade ou por várias sociedades. Domínio refere-se a um corpo organizado de conhecimentos associados a uma área. Neste sentido, a matemática, a música e a química, por exemplo, podem ser consideradas domínios. Contribuições criativas promovem mudanças em domínios. É essencial, portanto, que o indivíduo tenha conhecimentos acerca do domínio a fim de introduzir variações no mesmo. Os indi- víduos mais prováveis de transformarem um domínio são aqueles que conhecem a fundo os seus princípios, detectam suas inconsistências e procuram estender suas fronteiras (Feldman, Csikszentmihalyi \& Gardner, 1994). Segundo Csikszentmihalyi (1996), domínios que têm procedimentos claros, informações integradas, são acessíveis e ocupam uma posição central na cultura, possibilitam aos indivíduos introduzirem inovações em seus sistemas quando comparados a domínios pouco estruturados.

Uma resposta criativa tem mais probabilidade de ocorrer quando o indivíduo tem amplo acesso à informação relativa a um domínio (por meio de livros, revistas, internet, relatórios, vídeos etc) e quando as informações pertinentes ao domínio são conectadas entre si, são claras, relevantes, aprofundadas, despertam o interesse do indivíduo e impulsionam o seu engajamento na área.

O terceiro componente do modelo é o campo, que inclui todos os indivíduos que atuam como “juízes”. Eles têm a função de decidir se uma nova idéia ou produto é criativo e deve, portanto, ser incluído no domínio (Csikszentmihalyi, 1996). É o campo que seleciona e retém o material a ser reconhecido, preservado e incorporado ao domínio. No domínio das artes, por exemplo, o campo é composto por professores, curadores de museus, críticos e colecionadores. Tais indivíduos conhecem o domínio e têm seu saber reconhecido.

Uma idéia nova pode não ser aceita se o campo for defensivo, rígido e imerso em um sistema social que não encoraja a criatividade. Em suma, caso as pessoas qualificadas de uma área não tenham interesse em investir na preservação de algo novo no domínio, dificilmente esse será incorporado. Cabe também ao criador convencer o campo de que sua idéia ou produto tem valor e deve ser incluída no domínio. Por outro lado, o campo pode também estimular a produção de idéias novas. Em certos períodos históricos, determinadas áreas foram mais valorizadas pelo campo e atraíram indivíduos mais talentosos, favorecendo o surgimento de idéias originais. Portanto, para que uma idéia nova seja aglutinada ao domínio é essencial que ela seja socialmente aceita. Uma idéia só pode ser considerada criativa quando for avaliada pelo grupo de experts (campo) como tal. Uma idéia ou produto pode ser julgado como não criativo em um dado momento e criativo posteriormente (ou vice-versa), uma vez que critérios de interpretação e julgamento podem mudar de tempos em tempos.

"O quanto de criatividade existe em um dado momento não é determinado somente por quantos indivíduos originais estão tentando mudar os domínios, mas também por quão receptivo à inovação é o campo. Assim, no caso de alguém desejar aumentar a freqüência de criatividade, pode ser mais vantajoso trabalhar ao nível dos campos do que ao nível dos indivíduos" (Csikszentmihalyi, 1999, p. 327). Neste sentido, um ambiente social que ofereça recursos, reconhecimento e oportunidades, aumenta a probabilidade de ocorrência de contribuições criativas.

Esse modelo sistêmico define criatividade como um ato, idéia ou produto que modifica um domínio existente ou transforma esse em um novo. Para que isso ocorra é necessário que o indivíduo tenha acesso a vários sistemas simbólicos e que o ambiente social seja responsivo a novas idéias. Para Csikszentmihalyi (1999), ao invés de focalizarmos exclusi- 
vamente no indivíduo, seria mais produtivo voltarmos nossa atenção a comunidades, uma vez que são essas que possibilitam a expressão da criatividade. O processo criativo não é apenas o resultado de ações individuais, mas é co-criado por domínios e campos (Csikszentmihalyi, 1988c).

As diferentes abordagens de criatividade aqui apresentadas enfatizam que, embora o indivíduo tenha um papel ativo no processo criativo, introduzindo novas combinações e variações, é essencial que se reconheça também a influência dos fatores sociais, culturais e históricos na produção criativa e na avaliação do trabalho criativo. A fim de se obter uma visão mais ampla do fenômeno criatividade, devemos levar em consideração a interação entre características individuais e ambientais, as rápidas transformações na sociedade, que estabelecem novos paradigmas e demandam soluções mais adequadas aos desafios que surgem, e o impacto do produto criativo na sociedade. Lembramos que, para se estimular a expressão criativa na escola, no trabalho ou em outro contexto, é necessário preparar o indivíduo para pensar e agir de forma criativa, bem como planejar intervenções nesses contextos a fim de estabelecer condições favoráveis ao desenvolvimento da criatividade.

\section{Referências}

Alencar, E.M.L.S. (1995). Criatividade. Brasília: Editora da Universidade de Brasília.

Alencar, E.M.L.S. (1996). A gerência da criatividade. São Paulo: Makron.

Alencar, E.M.L.S., Neves-Pereira, M., Ribeiro, R. \& Brandão, S. (1998). Personality traits of Brazilian creative scientists. Gifted and Talented International, 13, 14-18.

Alencar, E.M.L.S. \& Rodrigues, C. J. S. (1978). Relação entre tempo de ensino, localidade da escola e características comportamentais consideradas desejáveis e indesejáveis por professores do ensino do 1 grau. Arquivos Brasileiros de Psicologia Aplicada, 30, 75-93.

Amabile, T.M. (1983). The social psychology of creativity. New York: Springer.

Amabile, T.A. (1989). Growing up creative. Buffalo, NY: The Creative Education Foundation Press.

Amabile, T.M. (1995). Attributions of creativity: What are the consequences? Creativity Research Journal, 8, 423-426.

Amabile, T.A. (1996). Creativity in context. Boulder, CO: Westview Press.

Amabile, T.M. \& Gryskiewicz, M.D. (1989). The creative environment scales: Work Environment Inventory. Creativity Research Journal, 2, 231-253.

Amabile, T.M. \& Tighe, E. (1993). Questions of creativity. Em J. Brockman (Org.), Creativity (pp. 7-27). New York: Touchstone.

Arieti, S. (1976). Creativity. The magic synthesis. New York: Basic Books.

Barron, F. (1969). Creative person and creative process. New York: Rinehart \& Winston.

Chambers, J.A. (1973). College teachers: their effect on creativity of students. Journal of Educational Psychology, 65, 326-334.

Collins, M.A. \& Amabile, T. M. (1999). Motivation and creativity. Em R. J. Sternberg (Org.), Handbook of creativity (pp.297-312). New York: Cambridge University Press.
Csikszentmihalyi, M. (1988a). The domain of creativity. Trabalho apresentado no Congresso de Criatividade. Pitzer College, Claremont, Estados Unidos.

Csikszentmihalyi, M. (1988b). Society, culture, and person: a systems view of creativity. Em R. J. Sternberg (Org.), The nature of creativity (pp. 325-339). New York: Cambridge University Press.

Csikszentmihalyi, M. (1988c). Where is the evolving milieu? A response to Gruber. Creativity Research Journal, 1, 60-62.

Csikszentmihalyi, M. (1996). Creativity. New York: HarperCollins.

Csikszentmihalyi, M. (1999). Implications of a systems perspective for the study of creativity. Em R. J. Sternberg (Org.), Handbook of creativity (pp. 313-335). New York: Cambridge University Press.

Feldman, D.H. (1994). Creativity: dreams, insights, and transformations. Em D. H. Feldman, M. Csikszentmihalyi \& H. Gardner (Orgs.), Changing the world. A framework for the study of creativity (pp. 103-134). Westport, CT: Praeger.

Feldman, D.H., Csikszentmihalyi, M. \& Gardner, H. (1994). A framework for the study of creativity. Em D. H. Feldman, M. Csikszentmihalyi \& H. Gardner (Orgs.), Changing the world. A framework for the study of creativity (pp. 1-45). Westport, CT: Praeger.

Gardner, H. (1993). Creating minds. New York: Basic Books.

Gruber, H.E. \& Davis, S. N. (1988). Inching our way up to Mount Olympus: the evolving-systems approach to creative thinking. Em R.J. Sternberg (Org.), The nature of creativity (pp. 243-270). New York: Cambridge University Press.

Henessey, B.A. \& Amabile, T. M. (1988). The conditions of creativity. Em R.J. Sternberg (Org.), The nature of creativity (pp. 11-38). New York: Cambridge University Press.

Hill, K.G. \& Amabile, T.M. (1993). A social psychological perspective on creativity: intrinsic motivation and creativity in the classroom and workplace. Em S.G. Isaksen, M.G. Murdock, R.L. Firestein \&. D. Treffinger (Orgs.), Understanding and recognizing creativity: the emergence of a discipline (pp. 400432). Norwood, NJ: Ablex.

Kneller, G.F. (1976). Arte e ciência da criatividade. São Paulo: Ibrasa.

MacKinnon, D.W. (1965). Personality and the realization of creative potential. American Psychologist, 20, 273-281.

Simonton, D.K. (1988). Scientific genius. A psychology of science. New York: Cambridge UniversityPress.

Simonton, D.K. (1994). Greatness. Who make history and why. New York: The Guilford Press.

Starko, A.J. (1995). Creativity in the classroom. White Plains, NY: Longman.

Sternberg, R.J. (1985). Beyond IQ: a triarchic theory of human intelligence. New York: Cambridge University Press.

Sternberg, R.J. (1988). A three-facet model of creativity. Em R. J. Sternberg (Org.), The nature of creativity. Contemporary psychological perspectives (pp. 125-147). Cambridge: Cambridge University Press.

Sternberg, R.J. (1991). A theory of creativity. Trabalho apresentado no XIV School Psychology Association Colloquium. Braga, Portugal.

Sternberg. R.J. \& Lubart, T.I. (1991). An investment theory of creativity and its development. Human Development, 34, 1-31.

Sternberg, R.J. \& Lubart, T.I. (1993). Creative giftedness: a mul- 
tivariate investment approach. Gifted Child Quarterly, 37 (3), $7-15$.

Sternberg, R.J. \& Lubart, T.I. (1995). Defying the crowd. Cultivating creativity in a culture of conformity. New York: The Free Press.

Sternberg. R.J. \& Lubart, T. I. (1996). Investing in creativity. American Psychologist, 51, 677-688.
Torrance, E.P. (1975). Assessing children, teachers and parents against the ideal child criterion. The Gifted Child Quarterly, 24, 10-14.

Wechsler, S.M. (1993). Criatividade, descobrindo e encorajando. Campinas: Editorial Psy.

Wertheimer, M. (1959). Productive thinking. New York: Harper \& Row.

Recebido em 21.09.2001

Primeira decisão editorial em 24.06.2002

Versão final em 07.10.2002

Aceito em 10.12.2002 